\title{
Espondilodiscitis en posible relación con acupuntura. A proposito de un caso
}

\author{
Spondylodiscitis caused possibly acupuncture. About a case
}

\author{
Victor Manuel Lopez Mouriño ${ }^{1}$, Benigno Monteagudo Sánchez², Jose Lopez Castro ${ }^{1}$, Maria Cristina Gonzalez Sobrado . \\ ${ }^{1}$ Hospital Comarcal de Monforte de Lemos ${ }^{2}$ Hospital Arquitecto Marcide Ferrol.
}

\begin{abstract}
Resumen
Presentamos el caso de un paciente varón de 59 años que acudió a nuestras consultas por un síndrome general, y tras completar el estudio fue diagnosticado de Espondilodiscitis Piógena. El paciente se había sometido a sesiones de acupuntura por un dolor de espalda de evolución tórpida, no evidenciándose ninguna otra causa que pudiera justificar el cuadro clínico. Realizamos una revisión de casos similares recogidos en la literatura publicada hasta la fecha.
\end{abstract}

Palabras clave: espondilodiscitis, acupuntura, etiología, epidemiología.

\section{Introducción}

La espondilitis infecciosa, espondilodiscitis, es una infección poco frecuente que afecta a las vértebras y los espacios intervertebrales. $^{1}$

La acupuntura es una técnica que consiste en la inserción estratégica de finas agujas en puntos de la superficie corporal con fines curativos. Su origen es chino, la primera referencia registrada sobre la acupuntura se encuentra en el antiguo texto chino titulado "Huang Di Nei Jing Su Wen", (conocido como "Clásico de Medicina Interna- Libro de Preguntas Comunes del Emperador Amarillo"). Fue una tradición que perduró a través de los siglos, llegado el Siglo XVII entró en declive ya que estaba considerada una técnica irracional y vinculada a supersticiones. Un decreto del Emperador excluyó en 1822 la acupuntura del Instituto Médico Imperial, quedando relegada a los curadores rurales y algunos escolares se aferraron al conocimiento de esta práctica. El Gobierno Comunista restableció en 1949 los formularios tradicionales del remedio incluyendo la acupuntura, estableció institutos de investigación de la Acupuntura en los años 50 en China y la práctica estaba disponible en varios hospitales. En el mundo occidental, clásicamente, esta técnica estaba limitada a inmigrantes asiáticos, y fue reconocida como profesión en los 30 últimos años. La Acupuntura finalmente fue validada en los E.E.U.U. cuando una conferencia del consenso de los National Institutes of Health (NIH) señaló que había pruebas positivas de su eficacia, por lo menos en algunas condiciones.

La base de la acupuntura consistía en el aforismo: "Bu tong ze tong, tong ze bu tong", que significa "flujo libre: no hay dolor; no flujo libre: hay dolor". El dolor representaría una obstrucción en el flujo normal de Qi o fuerza vital. Actualmente, muchos practicantes han desechado el concepto de flujo del Qi y han adoptado un modelo neurológico, basado en que las agujas de acupuntura estimulan terminaciones

\begin{abstract}
We report the case of a 59 years old male patient who presented to our clinic for a general syndrome, and after completing the study, he was diagnosed with pyogenic spondylodiscitis. The patient had undergone acupuncture treatments due to lasting back pain, and no other cause that could explain this infectious disease involving the spine, was evidenced. In addition, we review similar cases reported in the literature published up to date.
\end{abstract}

Keywords: spondylodiscitis, acupuncture, etiology, epidemiology.

nerviosas y alteran funciones cerebrales, en particular las relacionadas con el dolor.

Las primeras agujas utilizadas para administrar los efectos terapéuticos de la acupuntura estaban hechas de piedra, hoy en día se emplean de acero inoxidable. Otros materiales que se emplearon en la antigüedad fueron: piedras afiladas, hueso, plata, oro y fragmentos de bambú.

\section{Caso clínico}

Varón de 59 años que es remitido a la consulta externa de Medicina Interna por síndrome general de 2 meses de evolución (astenia, anorexia, y pérdida de $5 \mathrm{Kg}$ de peso, no refería ningún síntoma específico, pero en la anamnesis dirigida por sistemas y aparatos señalaba un dolor dorsolumbar de características inflamatorias y fluctuante. El día de la consulta estaba asintomático. El paciente refería que había recibido sesiones de acupuntura con buen resultado, aunque efecto autolimitado, no recordaba complicaciones de la técnica, ni signos de sobreinfección en los puntos de inserción de las agujas (se habían realizado a lo largo de la columna vertebral, así como en otros territorios corporales).

En la exploración, el paciente presentaba buen estado general, apirético, consciente orientado, colaborador, auscultación cardiopulmonar normal, abdomen y extremidades sin hallazgos patológicos, ausencia de alteraciones cutáneas, adenopatías, esplenomegalia, y de dolor a la percusión de apófisis vertebrales, así como a la movilidad de extremidades.

La radiografía de tórax era normal, en la analítica únicamente se apreciaba VSG de $111 \mathrm{~mm} / \mathrm{h}$ y PCR de 4,3 mg/dl. Las serologías (incluído VIH), resultaron negativas. En la TAC Torácica (Figura 1) se apreció alteración de la grasa prevertebral a nivel de D8-D9 asociada a erosión de platillos vertebrales superior e inferior de D9D10 y esclerosis subcondral de ambos cuerpos vertebrales, con disminución de la altura vertebral de D9. La Resonancia Magnética (Figura 2) se informó como: "protrusión global de los discos D6D7, D7D8 y D8D9 que contactan con la cara anterior de la médula espinal sin comprimirla de forma significativa,estos hallazgos sugieren la presencia de cambios degenerativos espondilodiscales; áreas hipointensas en T1 y T2 en los platillos vertebrales adyacen- 
tes al disco D9D10, en su porción anterior, que sugiere la presencia de cambios degenerativos Modic tipo II, y que coinciden con proliferación osteofítica anterior en platillos vertebrales al mismo nivel.". Se procedió a biopsiar esta última lesión (Punción aspiración por aguja fina guiada por TAC), enviándose muestras a Microbiología y Anatomía Patológica, con los siguientes resultados:

- PCR para micobacterias: negativo. Baciloscopia: negativo. Cultivo de micobacterias: negativo.

- Cultivo de biopsia quirúrgica: se aisla en 2/4 muestras Corynebacterium sp. PCR para micobacterias: negativo. Baciloscopia: negativo. Cultivo de micobacterias: negativo

- Citología de PAAF de masa paravertebral: sin evidencia de células malignas.

Se interpretó el cuadro como espondilodiscitis D9-D10 por Corynebacterium sp-y se pautó tratamiento con levofloxacino durante 8 semanas, tras las cuales el paciente mejoro clínicamente, desapareciendo el dolor de espalda y normalizándose los reactantes de fase aguda. Se realizó asimismo Ecocardiograma transtorácico, que descartó imagen de vegetaciones sugestiva de endocarditis infecciosa. Dado que el paciente estaba apirético y el ecocardiograma era normal no se consideraron rentables los hemocultivos.

\section{Discusión}

La espondilodiscitis es una infección del cuerpo y el disco vertebral.

Representa de 2 a $4 \%$ del total de casos de osteomielitis y tiende a afectar sobre todo a la población adulta. La incidencia en las sociedades occidentales varía de 0,4 a 2,4 por cada 100.000 habitantes al año ${ }^{1}$. Su incidencia ha aumentado en los últimos años debido a una mayor cantidad de procedimientos quirúrgicos espinales, bacteriemia nosocomial, el envejecimiento de la población y la adicción a drogas intravenosas (si bien esta última causa ha descendido en los últimos años) $)^{2^{*}}$. La mayoría de las series recientes destacan su aparición en pacientes de edad avanzada (edad media de 50 a 60 años) con un claro predominio del sexo masculino ${ }^{3}$ Entre las enfermedades predisponentes más comunes se encuentran la diabetes, diversos estados de inmunodepresión y las neoplasias ${ }^{4}$. La mayoría de los casos se debe a diseminación hematógena de infecciones a distancia (microabscesos en el cartílago subcondral donde el germen aislado en un 80-90\% es Staphylococcus aureus), 0 vía retrógrada por infección genitourinaria previa (con predominio de bacilos gramnegativos), siendo menos frecuentes las causadas por propagación de infecciones desde tejidos adyacentes y las debidas a procesos invasivos de la colum$\mathrm{na}^{5}$. Constituye una enfermedad de difícil diagnóstico ya que su principal manifestación clínica es el dolor dorsolumbar, del cual sólo el 0,01\% corresponderán a espondilodiscitis, menos frecuente el dolor cervical. Los estudios mediante radiografía y tomografía muestran manifestaciones tardías, siendo la resonancia magnética el estudio de primer orden y más sensible para detectar signos más precoces. Los datos clínicos de alarma que deben dirigir hacia el despistaje de esta entidad en los pacientes con dolor dorsolumbar son:
Figura 1. TAC: alteración de la grasa prevertebral a nivel de D8-D9 asociada a erosión de platillos vertebrales superior e inferior de D9-D10 y esclerosis subcondral de ambos cuerpos vertebrales, con disminución de la altura vertebral de D9.

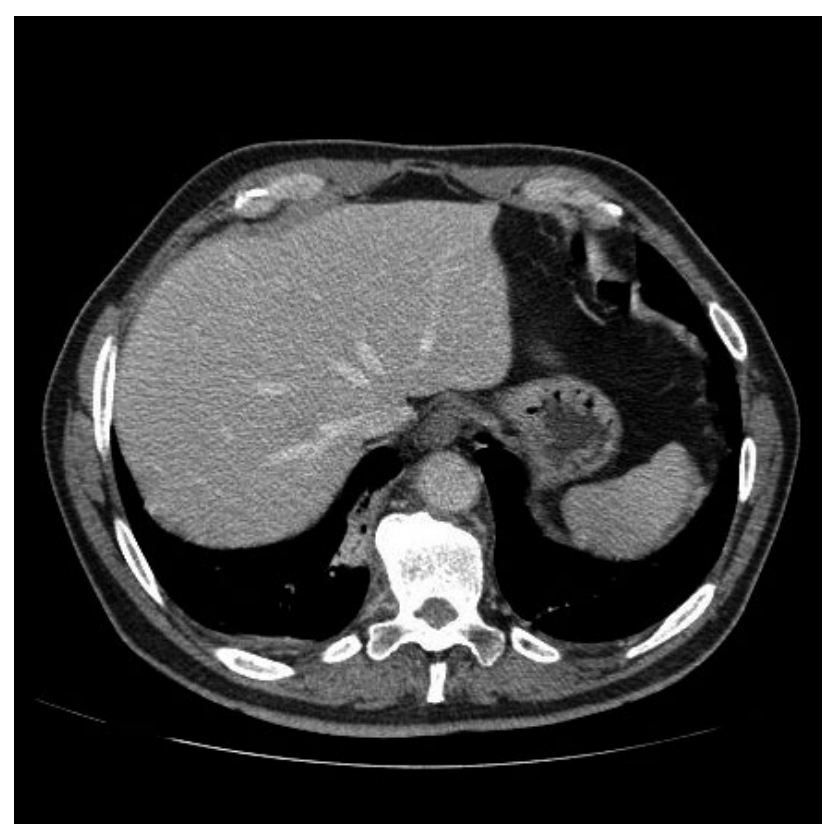

edad mayor de 50 años, fiebre, repercusión del estado general, inmunosupresión (farmacológica, VIH, insuficiencia renal terminal), diabetes mellitus, alcoholismo, cardiopatías valvulares, dolor de más de 4-6 semanas refractario a tratamiento convencional, traumatismo local previo e infección concomitante ${ }^{5}$.

Clínicamente se manifiesta como dolor de espalda de características inflamatorias que comienza de forma insidiosa durante semanas o incluso meses y no responde al tratamiento habitual. Un signo sugerente es el dolor a la presión-percusión de las apófisis espinosas. A medida que progresa la infección puede haber afectación medular 0 radicular. № siempre se acompaña de fiebre. Es fundamental el diagnóstico precoz para evitar complicaciones como la destrucción de los cuerpos vertebrales y la aparición de procesos supurados (colecciones paravertebrales), circunstancias que empeoran la morbilidad (capacidad funcional) e incluso mortalidad. La analítica es inespecífica, destacando la presencia de leucocitosis, pudiendo existir anemia normocítica y aumento de reactantes de fase aguda.

La negatividad de los hemocultivos y de las pruebas serológicas para descartar brucelosis obliga a practicar una punción-biopsia con fines diagnósticos y en último caso una biopsia a cielo abierto. En casos de no claros signos de discitis en las pruebas de imagen se puede plantear la biopsia como primera opción. También, estaría indicada la realización de un Mantoux. La extracción de hemocultivos 4 horas tras la realización de la biopsia del disco, puede aportar rentabilidad diagnóstica'.

La espondilodiscitis puede estar producida por una gran variedad de microorganismos. $S$. aureus es la bacteria más 
Figura 2. RMN



frecuente en todas las series y representa de 40 a $65 \%$ de los casos. Le siguen en frecuencia los bacilos gramnegativos (25 a $30 \%$ ) como Escherichia coli, Proteus sp. y Pseudomonas aeruginosa y cocos grampositivos del género Streptococcus sp. (7 a 10 \%) como S. pyogenes. La tuberculosis y la brucelosis son habituales en nuestro país y la frecuencia relativa de espondilodiscitis tuberculosa y brucelar es de 15 a $25 \%$ y de 20 a 50\%, respectivamente 4 .

La acupuntura es una técnica de tradición milenaria que en los últimos años ha resurgido, pero que no obstante no está exenta de riesgo. El caso clínico que acabamos de exponer es un ejemplo en el que la manipulación con agujas de acupuntura puede resultar en una espondilodiscitis, ya que el paciente no presentaba otros factores de riesgo (intervenciones, anestesias,...).Realizamos una búsqueda bibliográfica de casos similares publicados en la literatura. He $\mathrm{C}$ et al. Describieron el caso de un varón de 60 años con espondilodiscitis piógena combinado con osteomielitis vertebral y abscesos de psoas bilateral después de 7 sesiones de acupuntura, se aisló estreptococo del grupo C, y el tratamiento con antibiótico fue curativo ${ }^{6}$. Chiang GS et al. describieron el caso de una mujer de 80 años de espondilodiscitis por Staphylococcus aureus sensible a meticilina que había sido sometida sesiones de acupuntura por espondiloartrosis lumbar; la resonancia mostró datos sugestivos de espondilodiscitis D11-L1, no evidenciándose otros focos infecciosos; presentó una buena respuesta a tratamiento con cloxacilina durante 6 semanas. Los autores concluyeron acerca de la necesidad de formación profesional y garantía de asepsia en la técnica, para evitar el desarrollo de complicaciones sobre todo en pacientes de especial riesgo (inmunodeprimidos, valvulópatas cardíacos... .) ${ }^{2}$. Saeed MU et al., en una revisión sistemática de espondilodiscitis destacan que la espondilodiscitis raramente es causada por gérmenes anaerobios, pero en dos pacientes describieron el Corynebacterium sp. como causante de la misma ${ }^{7}$. Zohoun A et al., en un estudio retrospectivo que incluyó los pacientes diagnosticados de espondilodiscitis en un período de 4 años (2006-2009) en el Hospital Escuela Militar de Rabat, describieron un caso en el que la espondilodiscitis estaba causada por una coinfección de Mycobacterium tuberculosis y Corynebacterium sp. ${ }^{8}$. Arndt et al., en una revisión de 83 pacientes con espondiIodiscitis que precisaron tratamiento quirúrgico describieron 3 casos de espondilodiscitis por Corynebacterium sp. ${ }^{9}$ Perronne et al., en una serie de 80 casos, atribuyeron a uno de ellos una infección por Corynebacterium sp. ${ }^{10}$ Atalay B et al. describieron un caso de espondilodiscitis por Corynebacterium $s p$ en pacientes con insuficiencia renal ${ }^{11}$.

En conclusión, la acupuntura es una técnica en auge no exenta de complicaciones ${ }^{12}$, algunas de ellas potencialmente graves, como la espondilodiscitis infecciosa; por lo que se recomienda estar alerta a las mismas, para un diagnóstico y tratamiento precoces que reduzcan la morbimortalidad en los pacientes afectados.

\section{Bibliografía}

1. Cottle L, Riordan T. Infectious spondylodiscitis. J Infect. 2008;56:401-12.

2. Chiang GS, Tong K.Acupuncture causing methicillin-sensitive Staphylococcus aureus spondylodiscitis resulting in bacteremia and bacteriuria.J Am Geriatr Soc. 2014 Nov;62(11):2221-2.

3. Kim PS, Hsu W.Discitis in an adult following acupuncture treatment: a case report.J Can Chiropr Assoc. 2004 Jun;48(2):132-6.

4. Telo Crespo Rolando, Telo Haedo Rolando William, Alemán Cruz Pedro Nemesio, Rodríguez Torres Yerardys. Espondilodiscitis infecciosa. Rev Cubana Ortop Traumatol 2012; 26(1): 53-63.

5. A. Capa-Grasa, I. Flores-Torres, D. Gozalo-Arribas. Lumbar spondylodiscitis: Symptoms and risk factors in the early diagnosis.Rehabilitación (Madr).2010;44(1):8285.

6. He C, Wang T, Gu Y, Tian Q, Zhou B, Wu C.Unusual case of pyogenic spondylodiscitis, vertebral osteomyelitis and bilateral psoas abscesses after acupuncture: diagnosis and treatment with interventional management.Acupunct Med. 2015 Apr;33(2):1547.

7. Chiang GS, Tong K.Acupuncture causing methicillin-sensitive Staphylococcus aureus spondylodiscitis resulting in bacteremia and bacteriuria.J Am Geriatr SOC Nov2014; 62(11): 2221-2.-> Debe suprimirse, pues es igual a la referencia 2; debería asimismo revisarse en el texto y en la numeración del resto de citas de las referencias].

8. Saeed MU, Mariani P, Martin C, Smego RA Jr, Potti A, Tight R, Thiege D.Anaerobic spondylodiscitis: case series and systematic review.South Med J. 2005 Feb;98(2):144-8

9. Zohoun A1, Ngoh Akwa E, El Ochi M, Oragwu N, Akhaddar A, Albouzidi A, El Ouennass M.Bacteriological features of infectious spondylodiscitis at Mohammed V Military Teaching Hospital of Rabat.Braz J Microbiol. 2012 Oct;43(4):1327-31.

10. Arndt J, Charles YP, Koebel C, Bogorin I, Steib JP.Bacteriology of degenerated lumbar intervertebral disks.J Spinal Disord Tech. 2012 Oct;25(7):E211-6.

11. Perronne C, Saba J, Behloul Z, Salmon-Céron D, Leport C, Vildé JL, Kahn MF.Pyogenic and tuberculous spondylodiskitis (vertebral osteomyelitis) in 80 adult patients. Clin Infect Dis. 1994 0ct;19(4):746-50.

12. Atalay B, Ergin F, Teksam M, Caner $H$, Altinörs N.Spontaneous corynebacterium discitis in a patient with chronic renal failure.Spinal Cord. 2004 Jun;42(6):378-81.

13. Kim PS, Hsu W. Discitis in an adult following acupuncture treatment: a case report. J Can Chiropr Assoc. 2004 Jun;48(2):132-6. 